\title{
A FORMAÇÃO DE PROFESSORES EM PEDAGOGIA NA REGIÃO DO PONTAL DO TRIÂNGULO MINEIRO APÓS A LDB 9394/96
}

\author{
THE TEACHER TRAINING IN PEDAGOGY IN PONTAL DO TRIÂNGULO MINEIRO \\ AFTER LDB 9394/96
}

\author{
Armindo Quillici Neto ${ }^{2}$ \\ Sônia Aparecida Siquelli ${ }^{3}$ \\ Jaqueline Andrade Calixto ${ }^{4}$
}

\begin{abstract}
RESUMO: O presente trabalho refere-se ao resultado de uma pesquisa sobre a formação do pedagogo que atua como professor da educação infantil e do ensino fundamental (10 ao 5 ㅇ ano), realizada em três cidades da Região do Pontal do Triângulo Mineiro. Questionários foram aplicados e os dados tabulados analisando-se os índices de formação dos professores, o tempo de formação, uma avaliação sobre o curso que realizaram na educação superior e a contribuição para sua formação. Verificou-se que os professores ainda têm boas impressões sobre sua formação, mas revelaram certa insegurança no que diz respeito à aplicação do que viram na faculdade com seus alunos. O objetivo do presente artigo é estabelecer um debate sobre a formação de professores da educação infantil e do ensino fundamental, com vistas à formação no curso de Pedagogia. A formação do pedagogo tem atingido seus objetivos? O texto remonta às questões sobre o ensino no campo da formação desses profissionais, assuntos relativos à História da Educação e à própria Filosofia da Educação, apontando para o pensamento educacional em determinadas épocas da educação brasileira. As preocupações que motivaram este trabalho surgem de indagações sobre as indicações da LDB de 1996, em que se propôs repensar o lugar da formação de professores no
\end{abstract}

\begin{abstract}
The present study is the result of a research about the pedagogue education who acts as a teacher of Early Childhood and Elementary School Education (1st to 4th grades), held in three cities in the Region of Pontal do Triangulo Mineiro. Questionnaires were applied and tabulated the data in which it was found the indices to the teacher education, the time of the education, an assessment on the progress that has been done in Higher Education and their contribution to their training. It was found that the teachers still have good impressions about their training but revealed some uncertainty as regarding the application of what they have taught their students in university. The objective of this Article is to establish a debate about the teachers training of Early Childhood Education and Elementary Education, with a view to the training in Pedagogy Course. The formation of the Pedagogue has achieved its objectives? The text goes back to the issues about the teaching in the field of teacher education subjects relating to the History of Education and Philosophy of Education, pointing to issues of educational thinking in certain periods of Brazilian education itself. The concerns that motivated this research arise from questions about the investigations and indications of the LDB 1996, which proposed rethinking the place of teacher training
\end{abstract}

\footnotetext{
1 Trabalho é resultado da pesquisa realizada com fomento Fapemig, Edital Universal 2009.

2 Doutor em Educação pela Unicamp. Docente da Faculdade de Ciências Integradas do Pontal - FACIP e do Programa de PósGraduação em Educação da Faced, da Universidade Federal de Uberlândia - UFU. E-mail: armindo@pontal.ufu.br

3 Doutora em Educação pela Universidade Federal de São Carlos - Ufscar. Professora de História da Educação Brasileira e Ética e Formação Docente do Mestrado em Educação, pela Universidade do Vale do Sapucaí-Univás. E-mail: soniasiquelli@ univas.edu.br

4 Aluna do Programa de Pós-Graduação em Educação, Mestrado, da Faculdade de Educação - Faced da Universidade Federal de Uberlândia - UFU. Tem Graduação em Pedagogia pela Faculdade de Ciências Integradas do Pontal - Facip/UFU. E-mail: jaquelineandradecalixto@yahoo.com.br
} 
Brasil. Os resultados demonstrados na pesquisa deixam uma questão fundamental: os professores estão satisfeitos com a formação realizada nos cursos de Pedagogia? A maioria diz que sim, mas uma parte significativa dos entrevistados optou por respostas intermediárias, respostas que colocam a formação atual em dúvida, sinalizando para a necessidade de se repensar o projeto de formação de professores no país.

Palavras-chave: Formação Superior. Pedagogia. Professores. LDB. in Brazil. The results in the research have left a key question: are the teachers satisfied with the training held in Pedagogy Courses? The majority says yes, but significant proportion of interviewees have chosen intermediate responses, answers that put the current training in doubt, signaling the need to rethink the model of teacher training in Brazil.

Keywords: Higher Education. Pedagogy. Teachers. LDB.

\section{Introdução}

Esta pesquisa realizada em três cidades do Pontal, região situada do Triângulo Mineiro, no estado de Minas Gerais, pretendeu identificar a influência da formação superior, especialmente dos cursos de Pedagogia e Normal Superior, na melhoria da prática pedagógica de professores que se mostraram empenhados em seu trabalho pedagógico da educação infantil e do ensino fundamental (10 ao 5o ano), e que tinham formação em Magistério de ensino médio. Foram feitos contatos com os respectivos secretários de educação municipais para agendamento da primeira visita às cidades, identificadas aqui como (A), (B) e (C), no cuidado ético das instituições investigadas. Esta visita aconteceu com o intuito de entregar o ofício assinado pelo coordenador da pesquisa e professor da Universidade Federal de Uberlândia UFU, visando apresentar o projeto e a proposta de trabalho. A pesquisa teve como objetivo, ainda, conhecer/identificar o que mudou na prática pedagógica dos profissionais que tinham Magistério Normal e que por força da Lei de Diretrizes e Bases da Educação, LDB no. 9394/96 e do Plano Nacional de Educação de 2001, tiveram que cursar Pedagogia e/ou Normal Superior.

A cidade (A) possui três escolas, que atendem à educação infantil, ensino fundamental e ao ensino médio, sendo duas municipais e uma estadual, com um número total de 30 professores no município, sendo que destes 24 buscaram formação superior em Pedagogia e Normal Superior. A cidade (B) possui sete escolas, duas estaduais e cinco municipais, sendo que seis delas atendem à educação infantil, ensino fundamental e ao ensino médio. Nesta cidade o número total de professores é de 118 e deste total, 65 buscaram formação superior após 1997. O desenvolvimento da pesquisa na cidade (C) aconteceu após a apresentação da proposta deste estudo ao responsável pela Secretaria de Educação do município que na ocasião demonstrou interesse em colaborar com os trabalhos. Porém diante de questões adversas e de dificuldades para a realização da pesquisa, somente cinco meses após o contato inicial foram retornados os questionários respondidos.

O texto é resultado de uma reflexão que foi motivada pela situação da formação de professores no Brasil, principalmente após a publicação da LDB de $n^{\circ} 9.394 / 96$. Identifica-se uma apatia dos professores em relação à sua formação e á sua preparação para o exercício do magistério. Não foi constatada uma preocupação com os ideais de formação de professores, bem como, com a formação dos estudantes e da própria sociedade. Desta forma faz-se necessário repensar os cursos de Pedagogia, que são os atuais formadores dos professores das crianças da educação infantil e do ensino fundamental.

A reflexão que se desenvolveu após a realização da pesquisa, principalmente com a análise dos dados, teve apoio na legislação educacional, de documentos governamentais buscando referências nos seguintes autores: Chamon (2006), Didonet (2006), Saviani (2007), Brzezinski (1996), Santos (2002), Scheibe (2007), Freitas (2002), Kosik (1969), dentre outros.

Este trabalho contou com uma análise que não respondeu somente ao que se refere à prática 
do professor, mas que busca entender as concepções de educação que permearam a formação destes. A questão que acompanha a pesquisa é voltada, ainda, para a tentativa de identificar as visões de homem, mundo e sociedade que objetivam os cursos formadores de professores.

\section{A realização da pesquisa: apontamentos dos dados coletados}

O número de questionários aplicados nos três municípios pesquisados foi: 14 no município (A), 30 no município (B) e apenas 7 no município (C) totalizando 51 questionários aplicados. Somando-se a estes, temos mais 72 questionários respondidos em pesquisa nas disciplinas de Filosofia da Educação e de Pensamento Filosófico Brasileiro, do curso de Pedagogia da Faculdade de Ciências Integradas do Pontal/UFU, aplicados durante o período de um ano, o que resultou num total de 123 questionários aplicados a professores da região do Pontal do Triangulo Mineiro.

Em relação aos 123 participantes da pesquisa $97,6 \%$ são do sexo feminino e $2,4 \%$ do sexo masculino. A faixa etária pesquisada foi dos 20 aos 50 anos, sendo que $1 \%$ tem menos de 20 anos, $5 \%$ entre 20 e 29 anos, $44 \%$ entre 30 e 39 anos, $43 \%$ entre 40 e 49 anos, e $7 \%$ com 50 anos ou mais. Quanto à formação, estes $64 \%$ têm formação em Pedagogia, 19,5\% em Normal Superior, 10,5\% em outras licenciaturas, $1 \%$ em pedagogia e licenciatura, $1 \%$ em Normal Superior e Pedagogia e $4 \%$ não responderam a essa questão.

Os dados acima apontam para uma reflexão histórica sobre a educação brasileira. Segundo Chamon (2006a), até o século XIX, o Brasil, como sociedade agrária dividia-se em duas classes sociais: senhores e escravos, e neste contexto as mulheres estavam excluídas de participarem de qualquer ato público. Com o domínio português e a imposição de suas leis e costumes, ocorreu a doutrinação católica pelos padres jesuítas submetendo mulheres de variadas classes à obediência aos seus maridos. Porém ao longo deste mesmo século ocorreram indícios de mudanças importantes, o que levou a uma participação mais significativa das mulheres na vida da sociedade, como:

um maior espaço de mobilização de suas mulheres [...], as mulheres das camadas populares ganhavam o espaço público como trabalhadoras no comércio e nos serviços [...], ocorreu a penetração de diferentes credos e ideologias filosóficas oriundas do continente europeu fazendo com que o pensamento escolástico, originário de Portugal e até então hegemônico no Brasil, passara a sofrer oposição. (CHAMON, 2006b, p. 68).

Conforme apontado pelo autor, a tendência que foi se estabelecendo sobre a participação das mulheres na vida da sociedade é a de que elas buscassem uma atuação mais próxima da educação. Sendo assim, Tardif (2002a, p.76) contribui para uma reflexão de que o papel das mulheres seria o de atuar em serviços peculiares às ocupações femininas. Da mesma forma, optar pela profissão de professor significa, entre outras, que a experiência pessoal na escola foi significativa na escolha do Magistério, que houve influências dos hábitos familiares na escolha da profissão, como dos pais concentrados nas tarefas ligadas ao ensino e também que ocorreu influência dos antigos professores na escolha da carreira e na maneira de ensinar.

Ainda com relação à pesquisa, o período em que os participantes realizaram sua formação se deu entre 1980 e 2008, sendo que 10,5\% cursaram no período de 1980 a 1990, 10,5\% de 1991 a 1996, 56\% no período de 1997 a 2008, 21\% estão cursando e 2\% não responderam. Dos entrevistados $94 \%$ possuíam formação em Magistério ou curso Normal, $4 \%$ responderam que não possuíam esta formação e $2 \%$ não responderam.

Na década de 1990 a educação atingiu marcas importantes, notadamente no período após a publicação da LDB de número 9.394/96. No art. 62, por força da Lei, 
superiores de educação, admitida como formação mínima para o exercício do magistério na educação infantil e nas quatro primeiras séries do ensino fundamental, oferecida em nível médio, na modalidade Normal. (LDB, 9.394/96).

O Plano Nacional de Educação (PNE), aprovado pela Lei no. 10.172 de janeiro de 2001 propõe a formação inicial dos professores da educação básica, o estabelecimento de prazos para que eles adquiram formação superior, questão essa já discutida pela LDB 9.394/96 sendo assim, as metas do plano são:

Garantir, por meio de um programa conjunto da União, dos Estados e Municípios, que, no prazo de dez anos, $70 \%$ dos professores da educação infantil e de ensino fundamental (em todas as modalidades) possuam formação especifica de nível superior, obtida em curso de licenciatura plena em instituições qualificadas. (DIDONET, 2006a, p.161).

É importante observar que as professoras buscaram sua formação superior após o período de publicação da LDB de 1996, o que revelou que a União, os estados e os municípios passaram a cobrar tal formação em função da própria lei e dos documentos que se seguiram. Importante observar, ainda, que quando as professoras foram cursar o ensino superior, já eram portadoras de curso de Magistério e que naquele momento estavam atendendo a uma determinação da lei.

Do total das professoras entrevistadas, 33\% atuavam na educação infantil, $43 \%$ atuam na educação básica, $2 \%$ nas duas áreas e $22 \%$ não responderam. Em relação ao tempo de atuação profissional $2,4 \%$ atuavam a menos de dois anos, 16,2\% entre dois e cinco anos, $22,7 \%$ entre cinco e dez anos, $34 \%$ entre dez e vinte anos, $22,7 \%$ entre vinte e trinta anos, e $2 \%$ atuam a mais de trinta anos.

Segundo Brzezinski (1996, p. 208) a formação do professor para as séries iniciais de escolarização no curso de Pedagogia é uma tendência predominante. A adoção dessa tendência parece resgatar uma dívida histórica do curso de Pedagogia que licenciava o pedagogo atuar como professor primário sem, contudo, prepará-lo para ser professor. Desta forma, questiona-se se o curso de Pedagogia tem preparado o professor com as competências para a alfabetização.

Perguntou-se qual concepção pode ser considerada a mais utilizada pela maioria dos professores do curso que realizaram e $56 \%$ responderam $\operatorname{sim}(\mathrm{C})$ para tradicional, $1,6 \%$ responderam não (NC) para tradicional, 7,5\% responderam $\operatorname{sim}(C)$ para tecnicista, $13 \%$ responderam $\operatorname{sim}(C)$ para construtivista, 9,9\% responderam $\operatorname{sim}(C)$ para escolanovista, 9,7\% responderam $\operatorname{sim}(C)$ para critico, $1,6 \%$ não responderam, $0,7 \%$ responderam que não se aplicava.

Considerando suas próprias concepções de educação, 45,7\% das pessoas reponderam sim (C) para tradicional, 3,2\% responderam não (NC) para tradicional, 4,4\% reponderam sim (C) para escolanovista, 7,3\% reponderam sim (C) para critico, 3,4\% reponderam sim (C) para tecnicista, 32\% responderam $\operatorname{sim}(\mathrm{C})$ para construtiva, $2 \%$ não responderam, $2 \%$ responderam que não se aplicava.

Segundo Saviani (1987a, p.10) a concepção de Educação na pedagogia tradicional tem como papel a difusão da instrução, transmitir conhecimentos acumulados pela humanidade e sistematizados logicamente. A escola é organizada como uma agência centrada no professor, sendo que este transmite, segundo uma gradação lógica, o acervo cultural aos alunos. Os alunos, por sua vez, assimilam os conhecimentos que lhe são transmitidos. A iniciativa sempre é do professor, ele é o sujeito decisivo. Para a pedagogia tradicional a questão principal é aprender.

A concepção escolanovista no Brasil teve seu auge em 1932, com a publicação do Manifesto da Escola Nova. Apregoava-se uma escola pública e laica. A proposta dos Pioneiros da Educação era inspirada no pensamento de John Dewey. Para eles o local privilegiado da educação é a escola e o ideal educacional está centrado na criança. Segundo Cury (1978b, p.70), o ideal escolanovista baseia-se no pensamento moderno, voltado para as novas realidades sociais (cientifico - filosóficas).

A concepção critico-reprodutivista, apontada por Saviani (1987b, p. 19), compreende a educação com base em seus condicionantes sociais. Há uma dependência e uma reprodução da educa- 
ção em relação à sociedade. Conforme Saviani (2007c, p.396), o objetivo dessa teoria é compreender e explicar o modo de funcionamento da educação e não fornecer uma orientação pedagógica pra a prática educativa, motivo esse de tantas críticas.

Ainda de acordo com Saviani (2007d, p.380) a pedagogia tecnicista passa a ser hegemônica e configura a organização racional dos meios, o professor e o aluno ocupam posição secundária, relegados que são à condição de executores de um processo cuja concepção, planejamento, coordenação e controle ficam a cargo de especialistas supostamente habilitados, neutros, objetivos e imparciais.

Percebe-se uma contradição e uma dificuldade quando o professora precisa delimitar seu campo teórico de atuação, definido em qual modelo de formação ele acredita. Se parte significativa dos professores adotam a vertente tradicional $(45,7 \%)$ em sua prática e praticamente as mesmas pessoas acham que têm o construtivismo (32\%) como orientação pedagógica, é possível inferir que eles não conseguem identificar claramente quais são as tendências teóricas da educação?

Ao serem questionados se o curso superior proporcionou amadurecimento intelectual ou não, $82 \%$ responderam que $\operatorname{sim}(C)$ e $18 \%$ responderam que mais ou menos (PC). Em relação ao curso superior, foi indagado se este proporcionou o conhecimento de teorias inovadoras sobre a educação, sendo que, $75,6 \%$ responderam que $\operatorname{sim}(C), 22,8 \%$ responderam que mais ou menos (PC) e $1,6 \%$ responderam que não (NC). Santos (2002a) comenta que a formação de professores se faz tanto no campo da legislação quanto no desenvolvimento de diferentes competências no âmbito da cultura e no desenvolvimento da profissão:

no campo da legislação, as Diretrizes Curriculares Nacionais para a Parecer CNE/CP n 9/2001, definem seu parágrafo 3 artigo 6 , que os projetos pedagógicos dos cursos de formação de docentes precisam possibilitar a aquisição de diferentes competências que envolvem conhecimentos relacionados a uma cultura geral ampla, cultura profissional, conhecimento sobre crianças, jovens e adultos, conhecimento sobre dimensão cultural, social, política e econômica da educação, domínio das áreas de conteúdo que são objeto de ensino, conhecimento pedagógico e conhecimento advindo da experiência. (SANTOS. 2002b, P. Formação de Professores da Educação Básica, em nível superior, curso de Licenciatura, de graduação plena, aprovadas pelo Conselho Nacional de Educação, 158).

Quanto ao conhecimento de práticas inovadoras sobre a educação, 57,7\% responderam que o curso superior proporcionou essa prática (C), 39,8\% responderam que mais ou menos (PC), 1,6\% responderam que não (NC) e 0,9\% não responderam. Ana Lúcia Amaral (2002, p. 151), afirma que a formação Superior deve proporcionar uma sólida formação, que, só pode ser desenvolvida por universidades compromissadas com a formação e o desenvolvimento de professores capazes de aliar a pesquisa nos processos formativos. Somente assim a prática dos professores será criativa e inovadora.

Perguntando se a prática pedagógica foi modificada em relação ao período em que não tinha formação superior, $83 \%$ responderam que $\operatorname{sim}(C), 13,8 \%$ responderam que mais ou menos (PC), $1,6 \%$ responderam que não se aplicava e $1,6 \%$ não responderam.

Tardif (2002, p.236) revela que:

É preciso saber, porém, que todo trabalho humano, mesmo o mais simples e mais previsível, exige do trabalhador um saber e um saber-fazer. Noutras palavras, não existe trabalho sem trabalhador que saiba fazê-lo, ou seja, que saiba pensar, produzir e reproduzir as condições concretas de seu próprio trabalho. O trabalho -como toda práxis - exige, por conseguinte, um sujeito do trabalho, isto é, um ator que utiliza, mobiliza e produz os saberes de seu trabalho. Não poderia ser diferente com os professores, os quais realizam um trabalho que 
não é simples nem previsível, mas complexo e enormemente influenciado pelas próprias decisões e ações desses atores. (TARDIF. 2002b, p.236).

Quanto à relação com os alunos, se esta se modificou em relação ao período em que não tinham formação superior, $72 \%$ responderam que $\operatorname{sim}(C), 22,8 \%$ responderam que mais ou menos (PC), 3,2\% responderam que não se aplicava, 2\% não responderam. Segundo Libâneo (2005, p.89) a pedagogia contemporânea não pode mais desconhecer ao fortalecimento das subjetividades dos alunos, além de desenvolver também o sentimento de pertencimento à humanidade, à coletividade, implicando valores de compartilhamento e solidariedade.

Contudo ao observar as várias habilidades de um bom professor, destaca-se o uso de palavras de reforço positivo diante das respostas dos alunos, como forma de incentivá-los a participar da aula. A autora ainda comenta que, "quando o professor chega perto do aluno, quando o chama pelo próprio nome, há uma interação que faz o aluno se sentir sujeito do ato de aprender", (CUNHA, 2005, p. 145).

Para Tardif (2002c, p. 130) uma boa parte do trabalho docente é de cunho afetivo, emocional. Baseia-se em emoções, em afetos, na capacidade não somente de pensar nos alunos, mas igualmente de perceber e de sentir suas emoções, seus temores, suas alegrias, seus próprios bloqueios afetivos.

Em relação ao conhecimento sobre as diretrizes curriculares do curso que fizeram, $47 \%$ responderam que a conhecem (C), 43\% responderam que mais ou menos (PC), $8 \%$ responderam que não (NC), $1 \%$ responderam que não se aplicava e $1 \%$ não responderam. Também em relação o conhecimento dos Parâmetros Curriculares Nacionais, 58,5\% responderam que conhecia os PCNs (C), $30,8 \%$ responderam que mais ou menos (PC), $7,3 \%$ responderam que não havia nenhuma clareza (NC), $2,4 \%$ responderam que não se aplicava e $1 \%$ não responderam.

As diretrizes curriculares para o curso de Pedagogia, determinadas em maio de 2006, pela Resolução $n^{\circ} 1$, do Conselho Nacional de Educação, trouxeram à tona, novamente, as discussões a respeito da identidade do curso de Pedagogia e da sua intenção profissionalizante, estabelecida atualmente como licenciatura. O curso de Pedagogia destina-se, na sua atual formulação legal, à formação de professores para a educação infantil e aos anos iniciais do ensino fundamental, ao desenvolvimento de competências para o ensino nos cursos de nível médio, na modalidade normal; ao ensino na educação profissional na área de serviços e apoio escolar; às atividades de organização e gestão educacionais; e às atividades de produção e propagação do conhecimento científico-tecnológico do campo educativo.

A organização curricular do curso de Pedagogia só aconteceu dez anos após a aprovação da LDB no 9.394/96, pelo o esforço da Comissão de Especialistas de Ensino de Pedagogia em articular uma proposta plausível, que atendesse aos profissionais da área. Scheibe (2007a), em seu estudo sobre a trajetória das diretrizes curriculares do curso de Pedagogia acrescenta que:

Nesses anos, estiveram em declarada disputa distintas concepções a respeito da identidade e da organização do curso. À concepção de formação expressa nas reformas instituídas a partir do Governo de Fernando Henrique Cardoso, na esteira das mudanças educacionais neoliberais desenvolvidas na América Latina durante a década de 1990, contrapôs-se o pensamento social-crítico dos movimentos organizados pelos educadores em busca de uma formulação de políticas públicas de caráter democrático. (SCHEIBE, 2007b, p.47).

Os Parâmetros Curriculares Nacionais (PCN) foram elaborados pelo Governo Federal com a finalidade de propiciar elementos à elaboração e reelaboração do currículo escolar, tendo em vista um projeto pedagógico semelhante em todas as regiões brasileiras a fim de evitar disparidades, como até então acontecia. Não têm caráter de obrigatoriedade e, consequentemente, pressupõe-se que serão adaptados às particularidades locais. A importância do conhecimento desses parâmetros 
pelos professores é de imensurável seriedade, visto que se trata diretamente do seu cotidiano profissional e da consciência das ações políticas de que a educação é alvo.

Questionando-se se o currículo do curso que fizeram atendia às demandas atuais da sociedade, $37 \%$ responderam que $\operatorname{sim}(\mathrm{C}), 52 \%$ responderam que mais ou menos (PC), $7 \%$ responderam que não (NC), 1,6\% responderam que não se aplicava e 2,4\% não responderam.

Como visto acima, as diretrizes curriculares do curso de Pedagogia são recentes, e trouxeram mudanças significativas ao curso. $\mathrm{O}$ que pela LDB/96 foi designado como função do curso de Normal Superior foi delegado novamente ao profissional formado pelo curso de Pedagogia, como o ensino na educação infantil e nos anos iniciais do ensino fundamental. Essas mudanças são de crucial importância para ao estudante e para o profissional formado em ambos os cursos (Normal Superior e Pedagogia), pois afetam diretamente em suas carreiras.

Em relação ao sentimento de realização com a profissão no aspecto pessoal, $68,2 \%$ responderam que se sentem realizados, (C), 27,6\% responderam que mais ou menos (PC), 1,6\% responderam que não (NC), $1 \%$ responderam não que se aplicava $1,6 \%$ não responderam. Já no aspecto profissional, $59 \%$ responderam que $\operatorname{sim}(\mathrm{C}), 29 \%$ responderam que mais ou menos (PC), $5 \%$ responderam que não (NC), $1 \%$ responderam que não se aplicava e $6 \%$ não responderam. (comentar)

Quanto à prática, se esta se modificou nos últimos dez anos, 83\% responderam que sim (C), $9 \%$ responderam que mais ou menos ( $P C), 1 \%$ responderam que não $(\mathrm{NC}), 4 \%$ responderam que não se aplicava e $3 \%$ não responderam.

A formação profissional tem o dever de dar aporte teórico-prático, favorecendo as especificidades de cada profissão, sem ignorar as dimensões integrais da vida e do exercício profissional no mundo contemporâneo. A prática da pesquisa nas academias procede favorecendo o despertar do conhecimento, beneficiando a construção crítica dos saberes profissionais e, a autonomia do pensar, sem desvincular estes do contexto social, das práticas em que também são edificadas as habilidades cognitivas.

Entendemos que o curso deve proporcionar ao indivíduo mudanças em suas práticas profissionais e pessoais, pois favorece uma superação do senso comum pelo conhecimento científico de seu modo de vida, que pede reflexão constante da prática pelo individuo, além de potencializar a construção e difusão do conhecimento próprio por meio de pesquisa e o questionamento constante e autônomo pertinente as dificuldades vivenciadas.

Ao se questionar-se o salário atual teve alguma melhoria em relação à época em que não tinham formação superior, 19 \% responderam que $\operatorname{sim}(C), 33 \%$ responderam que mais ou menos (PC), $29 \%$ responderam que não (NC), 17\% responderam que não se aplicava e $2 \%$ não responderam.

Portanto, sob esse ponto de vista nem a realização financeira, nem a pessoal se separam, pois o ser humano precisa encontrar a felicidade e a sobrevivência, e estas andarão juntas quando se tratar de satisfação profissional.

Quando foi perguntado se o curso que fizeram carecia de maior carga horária, $46 \%$ responderam que $\operatorname{sim}(C), 14 \%$ responderam que mais ou menos (PC), $24 \%$ responderam que não (NC), 12 $\%$ responderam que não se aplicava e $4 \%$ que não responderam. Quando ao fato de o curso carecer de maior carga horária nas disciplinas de formação humana, $61 \%$ responderam que $\operatorname{sim}(C), 11 \%$ responderam que mais ou menos $(\mathrm{PC}), 13 \%$ responderam que não $(\mathrm{NC}), 6 \%$ responderam que não se aplicava e $9 \%$ não responderam.

cultivou-se, por um longo tempo, uma tradição de desqualificação tanto dos profissionais que atuam nas faculdades de educação quanto dos professores que elas formam nos cursos de pedagogia de licenciaturas e de pós-graduação. Essa tradição foi sendo atualizada em níveis cada vez mais complexos ao se definirem as concepções sobre o papel da universidade, estimulando certas áreas e cursos em detrimento de outros; separando o ensino da pesquisa; a graduação da pós-graduação, etc, consolidando-se representações de descrédito da educação e dos seus profissionais. (SCHEIBE, 2007c, p. 55). 
Ocorre de os professores poderem se formar em faculdades onde o ensino é dado de forma isolada, de maneira bastante técnica, se limitando à transmissão de conteúdo e na maioria dos casos não ocorrendo uma construção do conhecimento e discussões críticas no que concerne à realidade social.

Perguntado se o curso carecia de maior carga horária nas disciplinas de prática pedagógica, $72 \%$ responderam que $\operatorname{sim}(C), 13 \%$ responderam que mais ou menos (PC), $10 \%$ responderam que não (NC), $3 \%$ responderam que não se aplicava e $2 \%$ não responderam.

a prática pedagógica, por sua vez, é configurada como um trabalho coletivo da instituição, fruto de seu projeto pedagógico, o que implica que todos os professores responsáveis pela formação do pedagogo deverão participar, em diferentes níveis, da formação teórico-prática de seu aluno. Nesse sentido, a relação teoria e prática será considerada como eixo articulador da produção do conhecimento na dinâmica do currículo. (AGUIAR, 1999, p. 234).

Em relação a ter boas lembranças da faculdade que fizeram $76 \%$ responderam que sim (C), $13 \%$ responderam q mais ou menos (PC), $6 \%$ responderam que não (NC), $3 \%$ responderam que não se aplicava e $2 \%$ não responderam. Já em relação a não se ter boas lembranças, $12 \%$ responderam que $\operatorname{sim}(C), 24 \%$ responderam que mais ou menos (PC), $25 \%$ responderam que não (NC), $28 \%$ responderam que não se aplicava e $11 \%$ não responderam.

Perguntando-se possuíam boas lembranças dos professores do curso de graduação, $66 \%$ responderam que $\operatorname{sim}(C), 24 \%$ responderam que mais ou menos (PC), $2 \%$ responderam que não (NC), $5 \%$ responderam que não se aplicava e $3 \%$ não responderam. Quanto a não terem boas lembranças dos professores do curso de graduação, $11 \%$ responderam que sim (C), $24 \%$ responderam que mais ou menos (PC), $18 \%$ responderam não (NC), $31 \%$ responderam que não se aplicava e $16 \%$ não responderam.

No dizer de Gomes, defende um (a) professor (a) intelectual e, fundamentalmente, cidadão(ã) em processo contínuo de formação, capaz de articular a teoria e a prática, aprendendo e refletindo sobre a última, iluminada com teorias, construída e sistematizada inclusive por ele (a), que se forma através da prática coletiva, de cidadão (ã) solitário (a) para cidadão (ã) solidário (a), que desenvolva a escuta, a tolerância e o respeito com o (a) outro (a) o igual e, sobretudo, com o diferente, que seja capaz de construir uma identidade profissional buscando superar a suposta neutralidade, que tenha disponibilidade para o novo, ousando alternativas educacionais comprometidas com a aprendizagem do (a) aluno (a), com a igualdade e a justiça social, que seja menos consumidor das políticas oficiais de forma acrítica, para ser mais produtor de conhecimentos e que seja livre para educar para a cidadania, fundado no futuro, tendo o homem, o humano como projeto. (LIMA e GOMES, 2002, p. 181).

Questionando-se se consideram importante a exigência para que o (a) professor (a) da educação básica tenha formação superior, $98 \%$ responderam que $\operatorname{sim}(\mathrm{C})$ e $2 \%$ responderam mais ou menos (PC).

Os saberes da ação pedagógicos legitimados pelas pesquisas são atualmente o tipo de saber menos desenvolvido no reservatório de saberes do professor, e também, paradoxalmente, o mais necessário à profissionalização do ensino. Não poderá haver profissionalização do ensino enquanto esse tipo de saber não for mais explicitado, visto que os saberes da ação pedagógica constituem um dos fundamentos da identidade profissional do professor. De fato, na ausência de um saber da ação pedagógica válido, o professor, para fundamentar seus ges- 


\begin{abstract}
tos, continuará recorrendo á experiência, á tradição, ao bom senso, em suma, continuará usando saberes que não somente podem comportar limitações importantes, mas também não o distinguem em nada, ou em quase nada, do cidadão comum. Ora, para profissionalizar o ensino é essencial identificar saberes da ação pedagógica válidos e levar os outros atores sociais a aceitar a pertinência desses saberes. A profissionalização do ensino tem, desse modo, não somente uma dimensão epistemológica, no que diz respeito á natureza dos saberes envolvidos, mas também uma dimensão política, no que se refere ao êxito de um grupo social em fazer com que a população aceite a exclusividade dos saberes e das práticas que ele detém. (GAUTHIER, 1998a, p. 34).
\end{abstract}

Assim, o autor demonstra que o ensino possui distanciamento entre a teoria e a prática, e que este não deve ser fornecido de um jeito fragmentado e como pronto, acabado, de um jeito a se tornar limitado. Gauthier (1998b), indaga a dificuldade de a população em geral de reconhecer a pertinência e a especificidade de um saber pedagógico de alto nível se os próprios docentes não o fazem. Por intermédio do saber da ação pedagógica posto em evidência pela pesquisa e pela própria atividade dos professores e integrado na formação docente constitui como maneira de resolver esse problema. Desse modo, a formação inicial, recebida na universidade, encontraria aí um reconhecimento de sua pertinência.

\title{
3. Uma reflexão sobre a educação
}

O resultado da aplicação dos questionários sugere que se realize uma reflexão sobre a questão da formação do pedagogo. Aponta-se em alguns momentos o descaso dos professores com sua própria profissão, com o sentido de seu trabalho e com o significado social do desempenho das atividades de professor. Assim propomos uma análise tentando demonstrar algumas fragilidades e virtudes da formação nos cursos de Pedagogia.

Os dados coletados na pesquisa apontam que a maioria dos profissionais entrevistados é do sexo feminino e, possui formação em Pedagogia cursada no período de 1997 a 2008, revelando que a Lei de Diretrizes e Bases da Educação de 1996, - LDB 9.394/96 teve algum efeito em propor a formação superior para o professor da educação básica. Tal lei estabelece uma nova estrutura para a educação, formada por dois níveis escolares a educação básica e a educação superior. Em seus artigos 62,63 e outros, indica que os professores da educação básica devem buscar a formação superior e o seu amadurecimento intelectual. No entanto o que se constata é a morosidade com que se dá o processo de mudança na formação dos novos profissionais da educação. Por outro lado o país ainda não conseguiu estabelecer um projeto claro e definido para a formação dos professores da educação básica, especialmente na educação infantil e fundamental (10 ao 4ㅇano). Freitas (2002a) faz uma crítica à aprovação da Resolução CNE/CP no 133, de 2001, em relação ao papel dos cursos de Pedagogia.

A aprovação da Resolução CNE/CP no 133, em janeiro de 2001, sob a alegação de fazer cumprir as determinações do Decreto $n$ 우 3.276/99 e do Decreto no 3.550/2000 (que alterou o termo "exclusivamente" para "preferencialmente"), abriu mais um capítulo na discussão sobre o curso de pedagogia e as instâncias e o locus de formação dos professores para a Educação Básica, ao estabelecer definitivamente as regras para os pedidos de autorização de cursos de formação de professores: a formação de professores somente poderá acontecer em universidades e centros universitários (muito mais por conta das prerrogativas da autonomia do que por consentimento do MEC), e nos institutos superiores de educação, criados especificamente para esse fim. Com isso, inúmeros cursos de pedagogia em faculdades isoladas e integradas, que formavam professores, tiveram que se transformar em curso normal superior, ou permanecer como curso de pedagogia, formando exclusivamente o bacharel $3 / 4$ especialista para 
atuar nas tarefas de gestão, supervisão e orientação na instituição escolar. (FREITAS. 2002b. p. 3).

Também o Plano Nacional de Educação - PNE, aprovado pela Lei no. 10.172, de 09 de janeiro de 2001, estabeleceu as normas para que os municípios, os estados e a União implantassem suas diretrizes e os planos decenais de educação. No que diz respeito à formação de professores e à valorização do magistério, o plano reconhece que há, no Brasil, uma grande defasagem e aponta para três elementos fundamentais que sustentam uma política de valorização do magistério: a formação profissional inicial; as condições de trabalho, salário e carreira; e a formação continuada. (DIDONET, 2006b, p.149).

O plano cria diretrizes e metas para

melhoria das escolas, quer no tocante aos espaços físicos, à infra-estrutura, aos instrumentos e materiais pedagógicos e de apoio, aos meios tecnológicos, etc., quer no que diz respeito à formulação das propostas pedagógicas, à participação dos profissionais da educação na elaboração do projeto pedagógico da escola e nos conselhos escolares, quer, ainda, quanto à formulação dos planos de carreira e de remuneração do magistério e do pessoal administrativo e de apoio. (DIDONET, 2006c, p. 150).

Nas diretrizes estabelecidas pelo PNE, encontram-se elementos de valorização do magistério e a tentativa de dinamizar a prática da escola, pois a qualificação dos docentes é um dos grandes problemas a serem enfrentados pelos governantes nos próximos anos. A valorização dos profissionais implica, segundo o plano (DIDONET, 2006d, 155):

- uma formação profissional que assegure o desenvolvimento da pessoa do educador na condição de cidadão e profissional, o domínio dos conhecimento objetos de trabalho com os alunos e dos métodos pedagógicos que promovam a aprendizagem;

- um sistema de educação continuada que permita ao professor um crescimento constante de seu domínio sobre a cultura letrada, dentro de uma visão crítica e da perspectiva de um novo humanismo;

- Jornada de trabalho organizada de acordo com a jornada dos alunos, centrada num único estabelecimento de ensino e que inclua o tempo necessário para as atividades complementares ao trabalho em sala de aula;

- Salário digno, competitivo, no mercado de trabalho, com outras ocupações que requerem nível equivalente de formação;

- Compromisso social e político do magistério.

A reflexão que a realidade nos obriga a fazer é sobre a possibilidade da realização das metas estabelecidas no PNE. Em que medida os governos municipais, estaduais e o governo federal, criarão condições reais para realização dos objetivos colocados, sendo que a educação nacional ocupa índices desfavoráveis nos resultados das avaliações oficiais?

Uma das metas do plano que trata da formação inicial dos professores da educação básica é o estabelecimento de prazos para que estes adquiram formação superior. Trata-se de uma polêmica já anunciada por ocasião da publicação da LDB no. 9.394, de 20 de dezembro de 1996, que foi flexibilizada pelo próprio governo. Sendo assim, os objetivos do plano são:

garantir, por meio de um programa conjunto da União, dos Estados e Municípios, que, no prazo de dez anos, $70 \%$ dos professores da educação infantil e de ensino fundamental (em todas as modalidades) possuam formação específica de nível superior, obtida em curso de licenciatura plena em instituições qualificadas. (DIDONET, 2006e, p. 161). 
Há uma instabilidade nas diretrizes governamentais no que se refere sobre às propostas de formação de professores. Em dez anos o país instituiu e praticamente extinguiu um projeto nacional de formação de professores, que foi a criação do Instituto Superior de Educação e o Normal Superior. O país não tem um projeto claro e fundamentado para formar tais profissionais, nem mesmo condições de provocar uma mudança significativa na atual realidade.

\title{
4. Considerações finais
}

Não há clareza na definição de qual é o foco principal da formação, não se sabe se os cursos de Licenciatura devem oferecer uma formação com mais consistência pedagógica, ou se devem primar pelos conteúdos específicos, ou ainda, se uma formação geral deverá ser valorizada. A formação apressada e fragmentada não consegue gerar o que há mais de três décadas se vem reivindicando, uma formação técnica, fundada na aprendizagem de conteúdos e métodos específicos para a formação do professor e, uma formação política, baseada no conhecimento das tendências filosóficas e das políticas de formação adotadas pelos governos nos últimos anos.

Seguindo na direção da reflexão de Freitas (2002c), é a tentativa de mudança de foco sobre o lócus da formação de professores.

\begin{abstract}
Nossa hipótese é a de que as atuais políticas para graduação e também para a pós-graduação pretendem gradativamente retirar a formação de professores da formação científica e acadêmica própria do campo da educação, localizandoa em um novo "campo" de conhecimento: da "epistemologia da prática", no campo das práticas educativas ou da práxis. Vários estudos vêm firmando esta perspectiva, fortalecidos pelas reformas educativas das últimas décadas, em particular aqueles que se ancoram, em Tardiff e Perrenoud, entre outros (FREITAS. 2002d. p. 4).
\end{abstract}

Nossa concordância com o autor está justamente no aspecto do apressamento dos cursos de formação de professores por meio da redução da carga horária, utilizando-se o mínimo exigido pela lei e até mesmo o uso de disciplinas em modalidades a distância como forma de barateamento dos cursos. Esse é o caráter de apressamento da formação e o distanciamento da "formação científica" para os futuros professores, ou seja, a valorização extremada da prática pedagógica em detrimento dos fundamentos teóricos.

O discurso que se estabeleceu no meio educacional, é o da insistente busca da eficiência e competência na formação dos professores, principalmente nos cursos de formação pedagógica, nos cursos de licenciatura e no curso de pedagogia. Observa-se uma grande contradição, principalmente quando se trata da composição da carga horária e da abertura para que parte desta seja feita à distância. Muito já se falou sobre a insignificância da carga horária referente aos conteúdos pedagógicos das licenciaturas, mas na verdade o que se vê na prática de muitas instituições formadoras de professores é a insistência na redução da carga horária de tais disciplinas.

Considerando que a situação da prática docente não está resolvida na educação superior brasileira, o que dizer, então, da concepção dos professores sobre a formação dos futuros profissionais ou a concepção da educação superior brasileira? Na primeira metade da década de 1990, as autoras Vanilda Paiva e Mirian Jorge Warde, chamavam a atenção para o que estava ocorrendo no ensino superior, no que diz respeito à relação entre ensino e pesquisa:

tudo indica, pois, que estamos diante de um movimento de vai na direção contrária ao modelo humboldtiano de entrelaçamento entre ensino e pesquisa. 0 modelo americano de ensino superior de massa com cobertura tendencial universal, por meio de instituições públicas e privadas dedicadas fundamentalmente ao ensino e universidades de elite destinadas a formar as camadas dirigentes 
por intermédio de cursos que combinam formação profissional com uma ampla base geral e humanística (modelo Chicago) e nas quais também se realiza a pesquisa realmente importante e bem financiada, parece se espalhar pelo mundo (PAIVA. WARDE, 1994. p. 35).

Entendemos a educação como uma prática social que se realiza na relação do professor com o aluno, concordando com a ideia de que o homem é o realizador de sua realidade e que tudo o que circunda é obra nossa, obra do homem (KOSIK, 1969a, p. 110). Na pesquisa que realizamos tentamos buscar a concepção pedagógica que os profissionais da educação assimilaram em sua formação superior. O que nos motivou a realização desta pesquisa foi a compreensão da realidade como é vista por Kosik (1969b), que vê o homem como imperfeito, mas com a possibilidade de superação de sua imperfeição, entendendo que a educação é a possibilidade concreta de superação dessa imperfeição e da própria educação. $O$ que realiza a possibilidade da superação da imperfeição, segundo o autor, é o trabalho:

\footnotetext{
$\mathrm{Na}$ base do trabalho, no trabalho e por meio do trabalho o homem criou a si mesmo não apenas como ser pensante, qualitativamente distinto dos outros animais de espécies superiores, mas também como o único ser do universo, por nós conhecido, que é capaz de criar a realidade, O homem é parte da natureza e é natureza ele próprio. Mas é ao mesmo tempo um ser que na natureza, e sobre o fundamento do domínio da natureza - tanto a externa como a própria - cria uma nova realidade (...) (KOSIK, 1969c, p. 114).
}

A pesquisa revelou que os professores gostariam que seus cursos tivessem maior carga horária nas disciplinas de formação teórica, histórica, filosófica, sociológica, etc., que formam o fundamento da prática educacional. Por uma questão cultural ou até mesmo pela sua formação escolar, há pouca preocupação em relação aos registros da prática educacional e aos documentos que resguardam os princípios da educação. $O$ trabalho docente exige um comprometimento que vai além do simples ensinar conteúdos, é necessário estabelecer relações sobre o significado e o papel social dos conteúdos.

A educação brasileira vive uma crise que transita entre o acesso à maioria da população e a busca da qualidade para a construção de uma sociedade mais justa e consciente de seus limites e perspectivas. Se até a década de 1980 a grande preocupação foi garantir o maior número de vagas para a população nas escolas de educação básica, o debate que se estabeleceu a partir daí foi o de se utilizar as vagas existentes de forma mais racional, ou seja, pensar menos na construção de prédios e mais nas condições inerentes à qualidade da escola.

O debate em torno da busca da qualidade já era motivo de preocupação no período do governo Fernando Henrique Cardoso (1995 - 2003), o que resultou na publicação da Lei de Diretrizes e Bases da Educação Nacional, no. 9.394, de 20 de dezembro de 2006 na implantação do sistema de avaliação da educação superior, o provão na busca de recursos financeiros em organismos internacionais como o Banco Mundial e na modernização do sistema.

A Pedagogia investiga a realidade educacional, expressa objetivos e processos de metodologia, transmitindo ações pedagógicas, ou seja, os comportamentos e ações conscientes e voluntarias de construção de saberes. Por sua vez, o pedagogo é um profissional que deve desenvolver a prática educativa sempre ligada à construção de saberes e ao modo de ação, visando à formação humana. Ele deve investigar fatores que contribuem para a construção do ser humano na sociedade.

No entanto, cabe neste momento, uma reflexão sobre a situação da formação do pedagogo nos últimos anos, pois um país que privilegiou a formação tecnicista sem se preocupar com o que o professor tivesse uma formação ética e humana, vendo o aluno como um mero aprendiz de técnicas e habilidades para a aprendizagem e reprodução, constrói também uma sociedade pautada na técnica sem conseguir ver o humano na sua completude e realização. 


\section{Referências}

AGUIAR, M.A; SCHEIBE. Leda: Formação de profissionais da educação no Brasil: o curso de pedagogia em questão. Educação e Sociedade, ano XX, n 68, Dezembro/99.

BRASIL. Diretrizes Curriculares Nacionais para o Curso de Pedagogia e Licenciatura. Brasília. DF: 2006.

BRASIL. LDB (1996). Lei de Diretrizes e Bases da Educação Nacional. Brasília. DF: Senado 1996.

BRZEZINSKI, Iria. Pedagogia, pedagogos e formação de professores: busca e movimento. Campinas. SP. Papirus. 1996.

CHAMON, Magda Lucia. Trajetória de feminização do magistério: ambiguidades e conflitos. In: Vera Lúcia Ferreira Alves de Brito. (Org.). Professores: identidade, profissionalização e formação. 1 ed. Belo Horizonte/MG: Argumentum Editora, 2006.

CUNHA, Maria Isabel da. Formatos Avaliativos e concepção de docência. Campinas. Autores Associados. 2005. O bom professor e sua prática. Campinas. SP. Papirus. 1995.

CURY, Carlos Roberto Jamil. Ideologia e Educação Brasileira. Católicos e Liberais. São Paulo. Cortez e Moraes. 1978.

DAMIS, Olga Teixeira. Formação pedagógica do profissional da educação no Brasil: uma perspectiva de análise. In: AMARAL, Ana Lúcia e VEIGA, Ilma Passos Alencastro (Orgs.). Formação de professores: políticas e debates. Campinas, SP: Papirus, 2002.

DIDONET, Vital. Plano Nacional de Educação. Brasília. Líber Livro Editora. 2006.

FREITAS, Helena Costa Lopes de. Formação de Professores no Brasil: 10 anos de embate entre projetos de formação. Revista Educação e Sociedade. Vol. 23. N. 80. Campinas. Set. 2002.

GAUTHIER, Clermont (Org.). Por uma teoria da pedagogia. Pesquisas contemporâneas sobre o saber docente. Trad. Francisco Pereira de Lima. Ijuí. RS: Ed. Unijuí, 1998.

KOSIK, Karel. Dialética do Concreto. Rio de Janeiro. RJ. Paz e Terra. 1969.

LIBANEO, José Carlos. O Campo do Conhecimento Pedagógico e a identidade profissional do pedagogo. In: Pedagogia e pedagogos, para quê? São Paulo: Cortez, 2005. 200p. (8. ed.)

LIMA, M.S.L; GOMES, M.O. Redimensionando o papel dos profissionais da educação: algumas considerações. In: PIMENTA, Selma Garrido e GHEDIN, Evandro. (Orgs.). 2002.

PAIVA, Vanilda. WARDE, Mirian Jorge. Dilemas do ensino superior na América Latina. Campinas. SP. Papirus, 1994.

SANTOS, L. L. de Castro Paixão. Identidade Docente em tempos de Educação Inclusiva. In: AMARAL, Ana Lúcia e VEIGA, IIma Passos Alencastro (Orgs.). Formação de professores: políticas e debates. Campinas, SP: Papirus, 2002.

SAVIANI, Dermeval. Escola e Democracia. São Paulo. Cortez/Autores Associados. 1987.

Histórias das Ideias Pedagógicas no Brasil. Campinas/SP. Autores Associados. 2007.

SCHEIBE, Leda. Formação de Professores: políticas e debates. In: AMARAL, Ana Lúcia e VEIGA, IIma Passos Alencastro (Orgs). Formação de professores: políticas e debates. Campinas, SP: Papirus, 2007. 
TARDIF, Maurice. Saberes Docentes e Formação Profissional. Petrópolis: Vozes. 2002.

Recebido em setembro de 2014. Aprovado em novembro de 2014. 